\title{
FOREWORD
}

\section{Special Section on Software Agent and Its Applications}

Various information terminals and devices such as PCs, mobile phones, PDAs, IC chips, sensors and so on, have been developed and they can be tightly connected through the Internet. Software agents that collaboratively and intelligently process information on the Internet attract attention more and more. Conventional AI aims at developing intelligent systems that imitate a single person, but in the network era, it is indispensable to consider the environment surrounding the person and the relationship among people. "Agent" that autonomously solves problems interacting with people, other agents, and the environment becomes a modern approach of "AI" nowadays.

The IEICE Special Interest Group for Artificial Intelligence and Knowledge Processing (IEICE SIG-AI) has been working on agent technology and promoting a wide range of the research issues from basic theories to applications. We organized SAA (Software Agent and its Applications) Symposiums in 1997 and in 2000, and published three special issues of IEICE transactions by selecting the papers presented at SAA Symposiums [1]-[3].

We then started JAWS (Joint Agent Workshop and Symposium) in 2002 by merging SAA Symposium and MACC (Multiagent and Cooperative Computation) Workshop that was organized by JSSST (Japan Society for Software Science and Technology). Since 2003, IPSJ SIG-ICS (Information Processing Society of Japan, Special Interest Group for Intelligence and Complex Systems) and JSAI SIG-KBS (Japanese Society for Artificial Intelligence, Special Interest Group for Knowledge Based Systems) have joined JAWS. JAWS has been held annually and become the main agent conference that AI SIGs of four major IT societies in Japan co-organize. Papers presented at JAWS have been selected and published as 6 special issues or sections of transactions of IEICE, JSAI, and IPSJ [4]-[9].

This special section was planed jointly with JAWS 2006 held in Suzuka Circuit Hotel in October. Following the editing scheme taken by the previous issues, the deadline of paper submission was set one month after the conference, so the authors could reflect the comments given at the conference to their papers. Papers not presented at JAWS2006 were also accepted for submission. We received 46 papers for Japanese transactions and 15 papers for English transactions. After careful reviews, we accepted 18 papers for Japanese transactions and 4 papers for English transactions. Papers selected for Japanese transactions are categorized as follows.

- Model/Theory 7

- Mobile Agents/Ubiquitous Computing/P2P 4

- Agent-based Simulation 7

It is worth to remark that many papers related agent-based simulation have been accepted in this issue. This may show a research trend of agent technology in Japan. We expect this issue contributes to make the readers know the latest agent research activities in Japan and to promote the research field more active.

Finally, I would like to express my thanks to the editorial committee members of the special section. My special thanks go to the PC members of JAWS 2006, who vigorously reviewed many papers under a tight schedule. Without their help, it was very difficult to edit this issue.

\section{References}

[1] Special Issue on Software Agent and Its Applications, IEICE Trans. Inf. \& Syst. (Japanese Edition), vol.J81-D-I, no.5, May 1998.

[2] Special Issue on Software Agent and Its Applications, IEICE Trans. Inf. \& Syst. (Japanese Edition), vol.J84-D-I, no.8, Aug. 2001.

[3] Special Issue on Software Agent and Its Applications, IEICE Trans. Inf. \& Syst., vol.E84-D, no.8, Aug. 2001.

[4] Special Issue on Software Agent and Its Applications, IEICE Trans. Inf. \& Syst. (Japanese Edition), vol.J86-D-I, no.8, Aug. 2003. 
[5] Special Issue on Software Agent and Its Applications, IEICE Trans. Inf. \& Syst., vol.E86-D, no.8, Aug. 2003.

[6] Special Section on Agents, Trans. JSAI, vol.19, no.4, 2004.

[7] Special Issue on Software Agent and Its Applications, IEICE Trans. Inf. \& Syst. (Japanese Edition), vol.J88-D-I, no.9, Sept. 2005.

[8] Special Section on Software Agent and Its Applications, IEICE Trans. Inf. \& Syst., vol.E88-D, no.9, Sept. 2005.

[9] Special Issue on Multi-agent Systems from Theory to Practice, J. IPSJ, vol.47, no.5, 2006.

Editorial Committee:

Secretaries: $\quad$ Satoru Fujita (NEC), Kazunori Matsumoto (KDDI)

Members: Akihiko Ohsuga (Toshiba), Toramatsu Shintani (Nagoya Institute of Technology), Satoshi Kurihara (Osaka University), Takayuki Ito (Nagoya Institute of Technology)

Yasuhiko Kitamura, Guest Editor-in-Chief (Kwansei Gakuin University)

Yasuhiko Kitamura (Member)

was born in Nara, Japan in 1960. He received the B.E., M.E., and Dr.E. degrees from Osaka University in 1983, 1985, and 1988, respectively. From 1988 to 1990, he was a Research Associate in the Department of Electrical Engineering at Osaka City University, and from 1990 to 2003, he was a Lecture, an Associate Professor of the Department of Information and Communication Engineering. Since 2003, he has been a Professor in the Department of Informatics at Kwansei Gakuin University. His research interests include distributed AI, distributed problem solving, multi-agent systems, and realtime heuristic search. He is a member of IEEE, AAAI, JSAI, IPSJ, and ISCIE.

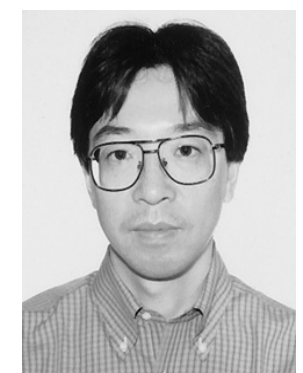

